\title{
A short guide to insect oviposition: when, where and how to lay an egg
}

Kevin M. Cury ${ }^{1}$, Benjamin Prud'homme ${ }^{2}$, Nicolas Gompel ${ }^{3}$

\author{
Addresses: \\ ${ }^{1}$ Department of Neuroscience and the Mortimer B. Zuckerman Mind Brain Behavior \\ Institute, Columbia University, New York, NY, USA \\ ${ }^{2}$ Aix-Marseille Université, CNRS, IBDM, Institut de Biologie du Développement de Marseille, \\ Campus de Luminy Case 907, 13288 Marseille Cedex 9, France \\ ${ }^{3}$ Ludwig-Maximilians Universität München, Fakultät für Biologie, Biozentrum, Grosshaderner \\ Strasse 2, 82152 Planegg-Martinsried, Germany
}

\begin{abstract}
:
Egg-laying behavior is one of the most important aspects of female behavior, and has a profound impact on the fitness of a species. As such, it is controlled by several layers of regulation. Here, we review recent advances in our understanding of insect neural circuits that control when, where and how to lay an egg. We also outline outstanding open questions about the control of egg-laying decisions, and speculate on the possible neural underpinnings that can drive the diversification of oviposition behaviors through evolution.
\end{abstract}

Keywords: insect oviposition; neuronal circuits; evolution of behavior

\section{INTRODUCTION}

Egg-laying is a dominant aspect of the reproductive biology of insects. With the few exceptions of larviparous insects, or insects providing parental care to their progeny, the deposition of an egg on a given substrate represents the last decision a female insect makes in favor of her progeny. There is therefore a heavy evolutionary weight on the process of how to lay an egg, and on the decision of when and where to lay an egg. Natural selection seems to have affected these two aspects - the process and the decision - in different ways, leading to a contrasting pattern of overall conservation of the former, and diversification of the latter.

The need to tightly regulate when and where to lay an egg demands neuronal controls acting at multiple levels (e.g. peripherally, centrally) and across a wide range of timescales, along with the coordination between these controls. A gravid female will first need to commit to the laying of eggs, and switch her behavioral drive toward that goal. This decision process is initiated by mating-derived cues that promote egg-laying behaviors immediately and durably. Subsequently, the female must find a suitable site for egg deposition, detecting and exploiting 
multimodal sensory cues associated with preferred substrates to guide this search. Finally, the female must execute the decision, releasing a tightly coordinated sequence of internal and external behaviors that culminate in the deposition of the egg in or on the substrate. Below, we review the neurons and circuits involved in the control of when, where and how insects lay eggs, highlighting their similarities over long phylogenetic distances, as well as their differences. Elaborating on this overview, we discuss outstanding questions about the control of oviposition and speculate on what neuronal changes likely evolved to accommodate the diversification of oviposition behaviors observed across insects.

\section{WHEN TO LAY AN EGG}

The timing of oviposition is not simply a matter of a site suitability, it is largely conditioned by changes in a female's internal state. The phenomenology of these temporal changes has been identified and extensively described during the $20^{\text {th }}$ century. It is governed by successful mating in the first place, but is also influenced by circadian and seasonal rhythms. The mechanisms underlying the temporal control of oviposition, however, have only recently began to be unraveled. What are the precise signals? How does a female insect sense these external triggers? How is the information relayed to her brain or to other organs involved in egg production?

The notion of a post-mating switch, a radical change in the overall reproductive drive of a female, breaks down in a suite of smaller behavioral and physiological changes geared towards egg production - packing particular food resources - and egg deposition - actively searching for an oviposition site (reviewed in (Gillott, 2003)). This implies the existence of molecular triggers, sensory receptors, and likely entire neuronal circuits and molecular pathways, which distribute the information and determine sustained motor and metabolic changes.

\section{Post-mating switch}

While insect reproductive behaviors are innate and produced by a tightly regulated developmental program (Arthur et al., 1998), these behaviors are subject to modulation. The post-mating switch of a female insect is a clear example of modulation, one for which the causal link between a complex stimulus (copulation) and the behavioral output is understood at the genetic and neuronal level in many organisms.

The female post-mating switch has been described in several insect species (reviewed in (Gillott, 2003; Lenschow et al., 2018), however, it is best understood in Drosophila. In D. melanogaster, the post-mating switch becomes manifest within minutes or hours of mating 
(Mack et al., 2006; Rezaval et al., 2014) and is sustained over days (Ram and Wolfner, 2007). It entails visible and durable changes in behavior including the rejection of courting males, and increased locomotor activity (Ferguson et al., 2015) and feeding (Carvalho et al., 2006). In particular, mated female flies develop a strong appetite for certain nutrients favorable to egg production such as polyamines (Hussain et al., 2016), in line with the increase in egg production triggered by mating (Heifetz et al., 2000; Soller et al., 1999). The post-mating response also reflects in an abrupt modification of gene expression (McGraw et al., 2008), notably in the female reproductive track (Mack et al., 2006) and likely in a tissue-specific manner in other parts such as the fat body or the brain (McGraw et al., 2008). Interestingly, while the suite of post-mating female responses is a robust signature of each species, there is also noticeable natural variation for these responses within-species that can for instance be measured in different levels of post-mating gene expression between flies from different geographical origins (Delbare et al., 2017).

\section{Sensing the mated state}

In sensory terms, mating involves at least two modalities: 1) chemosensation, through the molecular load delivered by the male to the female reproductive tract, and 2) mechanosensation, through the act of copulation per se, or possibly the stretch of spermstorage organs when they are filled

Chemosensation. The male ejaculate contains, in addition to spermatozoids, a fast evolving cocktail of hundreds of proteins, peptides and transcripts (e. g., (Bono et al., 2011; Findlay et al., 2008; Kelleher et al., 2009)), as well as pheromones (e. g., cis-vaccenyl acetate or cVA, (Brieger and Butterworth, 1970)). These proteins encompass a variety of molecular functions meant to facilitate sperm transfer - including proteases, odorant binding proteins, and molecules involved in lipid metabolism - while a subset act as triggers capable of influencing the post-copulatory behavior of the female. The best characterized of these molecules, Sex Peptide (SP), was identified in Drosophila (Chen et al., 1988). It is not particularly well conserved across insects, but the study of its function offers an explicit framework to think of chemical triggers for post-mating responses. Upon transfer to the female genital system, SP binds to Sex Peptide Receptor (SPR) (Yapici et al., 2008), a receptor expressed in the female reproductive system, and modulates its signaling. Specifically, SPR is expressed and active in a handful of internal sensory neurons that innervate the female reproductive tract and its lumen (Hasemeyer et al., 2009; Yang et al., 2009b). These sensory neurons, genetically identified as expressing both the DEG/ ENaC protein Pickpocket and transcripts of the sexspecific transcription factors fruitless (fru) and doublesex (dsx) (Hasemeyer et al., 2009; Rezaval et al., 2012; Yang et al., 2009a), are necessary and sufficient to mediate the post- 
mating state of a Drosophila female. Their projections to the abdominal ganglion are relayed to the higher brain (dorsal protocerebrum) by second-order neurons known as SAG (Feng et al., 2014). In short, SP binding to SPR in sensory neurons innervating the uterus reduces the activity of these neurons, which in turn lowers their activation of SAG neurons (Feng et al., 2014).

Other aspects of the suite of post-mating phenotypes are also sensed through SPR signaling, but independently of SP, or indirectly. For instance, the enhanced appetite for polyamines in mated females described above results from increased SPR expression and signaling directly in chemosensory neurons of the mouthparts and antennae that detect polyamines. The modulation happens not via SP, but via other ligands of SPR produced by the female, the MIPs (Hussain et al., 2016). Another example is the stimulation of egg production regulated by the hormone ecdysteroid upon mating and in response to SPR signaling (Ameku and Niwa, 2016). In both examples, the mechanism by which information regarding copulation flows from the reproductive tract to distant body parts, affording these physiological changes, remains unclear. In the case of polyamines, the modulation happens equally well in females mated with males mutant for SP, indicating that other initial triggers are involved, possibly some of the many other seminal fluid proteins. Like SP, they may be mostly active in the female reproductive tract with their physiological effects somehow relayed to other parts of the body (chemosensory organs, ovaries, etc.). In any case, the question of these relays remains open. On one hand, some of the male seminal fluid molecules (Sitnik et al., 2016) may pass to the hemolymph and act as endocrine agents in a systemic way. Particular organs or cells in distant regions may specifically respond to these circulating agents, promoting particular post-mating responses. Non exclusively, the information picked up by the sensory system innervating the uterus upon mating may be distributed throughout the nervous system by means of dedicated circuits (Feng et al., 2014), or more broadly by the secretion of neuromodulators. Such a role for neuromodulation has in fact been implicated in $D$. melanogaster, where a small number of abdominal ganglion neurons, which release the biogenic amine octopamine (OA) and show extensive innervation of the lower reproductive tract, appear required for the robust exhibition of post-mating behaviors (Rezaval et al., 2014).

Little is known of the molecular and neural mechanisms underlying post-mating switches in other insects, but there are reasons to think that the overarching principles are similar to $D$. melanogaster. SP is not a universal trigger, and was in fact only found in few insect groups (Kim et al., 2010), suggesting the existence of alternative triggers. In Anopheles mosquitoes, for instance, a steroid hormone, 20-hydroxyecdysone, assumes a similar role as SP (Gabrieli 
et al., 2014): it is transferred from males upon copulation and appears necessary and sufficient to elicit a series of physiological and behavioral changes in females, including egg laying and the reluctance to re-mate. Other elements of similarity in post-mating mechanisms have also been suggested from studies in moths, particularly the idea of cross-talk between neuronal circuits and physiological changes, such as changes in pheromone production (Delisle et al., 2000). In the Mediterranean fruit fly, Ceratitis capitata, there are significant changes in gene transcription post-mating, but their magnitude is more modest than in D. melanogaster, and the changes in immune-response gene expression seen in D. melanogaster are absent from Ceratitis (Gomulski et al., 2012). This suggests that, although the general logic of one or a few triggers affecting multiple aspects of insect physiology and behavior is maintained, the underlying mechanisms evolve rapidly.

Mechanosensation. There is surprisingly little literature that explores the role of mechanosensation in sensing mating and triggering post-mating responses in insects. Yet, there are all reasons to think that this modality is also involved in the switch. The external genitalia of female insects are covered with mechanosensory bristles and sensillae (Snodgrass, 1935; Taylor, 1989). While these organs may play a role during the process of oviposition, they may also be stimulated during copulation (Yassin and Orgogozo, 2013). Perhaps analogous, a single pair of bristles on the genital claspers of male D. melanogaster are necessary for maintaining proper posture during copulation (Acebes et al., 2003). There is also circumstantial evidence that the female insect reproductive system senses mechanical stimulation, for instance in response ovulation (Gou et al., 2014) (see below) or through copulation, resulting in removal of a previous male's sperm from the spermathecae (von Helversen and von Helversen, 1991).

\section{Circadian and seasonal modulation of when to lay an egg}

The phenomena described above are strictly triggered by the act of mating itself, either immediately or shortly thereafter. While this act strongly influences the exact time of egg laying (Brady, 1974), "when" an insect lays an egg is also modulated by cyclical variations occurring throughout the day and across seasons, affecting factors such as photoperiod, temperature, and food availability (Brady, 1974).

The effects of circadian rhythms on oogenesis and oviposition are particularly well characterized in different Drosophila species (Allemand, 1974, 1976a, 1976b, 1976c, 1977). Monitoring the oviposition activity of mated D. melanogaster females under 12:12 day/night cycles, Allemand observed consistent and recurrent peaks of egg laying at the onset of each 
dark phase. Unlike several circadian behaviors, which require an entrainment (typically light cycles), the daily rhythm of egg laying persists in an aperiodic environment for up to several hundred generations (Allemand, 1976a; Sheeba et al., 2001). This is not generally true for all insects, and some species such as Oncopeltus quickly lose rhythmicity in egg laying in the absence of light cycles (Brady, 1974). Allemand made two additional interesting observations: 1) that the process of oogenesis is also circadian and coordinated with oviposition (Allemand, 1976a) and 2) that the variation in circadian rhythms across related species ranged from small to large. While different species of the genus Zaprionus (drosophilids closely related to Drosophila) showed very similar circadian rhythms (Allemand, 1976c), species of the D. melanogaster group presented striking species-specific differences in their rhythms (Allemand, 1974).

Perhaps in line with the persistence of rhythmicity under aperiodic conditions, the molecular and neural substrates underlying oviposition rhythms seem to be distinct from the circadian clock known to modulate other behaviors, and remains unidentified (reviewed in (Manjunatha et al., 2008)). (Manjunatha et al., 2008) speculate that the integration of mating signals, egg production and circadian rhythmicity is likely happening in the abdominal ganglion, but this remains to be examined.

\section{What affords the sustained post-mating state?}

The timing of oviposition is hence tightly regulated by a female insect's physiological state. Mechanisms that link this behavioral output with factors that track mating status or the photoperiod likely rely upon the function of slow-acting neuromodulators and perhaps also upon specified circuits. In Drosophila, SP was shown to bind to sperm, and its gradual release from the female's sperm storage organs over days following mating ensures a sustained mating state (Peng et al., 2005). But other mechanisms may mediate the persistence of a postmating state. Recent experiments in D. melanogaster argued that mechanical stretch of the female reproductive tract resulting by an egg during ovulation serves as a cue to promote the active search of egg-laying substrates. In other words, the act of laying eggs, one of the immediate post-mating responses, maintains the female fly in a sustained mating state (Gou et al., 2014).

\section{WHERE TO LAY AN EGG \\ Behavior: Insects lay eggs in a broad repertoire of niches}

Once the question of "when" is behind and the time has come for gravid females to deposit their eggs, they need to find a good location. Because larvae have limited ability to change their habitats, gravid females are very selective when it comes to choosing an oviposition 
substrate. They look for substrates that will protect eggs and larvae from predators and pathogenic microorganisms, and sustain larval development. Insects in general use a plethora of different oviposition substrates, a non-exhaustive list includes: soil (beetles, flies, etc.); plants (all parts, all stages) (countless phytophagous insects); vertebrate wounds (flies); insect larvae (parasitic wasps, leafhoppers); the body of insects or spiders (parasitic wasps); water (mosquitoes); decaying wood, fruits, animals (all saprophagous insects) see (Carson and Kaneshiro, 1976; Kambysellis and Heed, 1971). Even among fairly closely related species, e.g., within Drosophilidae, an extravagant diversity of oviposition substrates has been documented: living crabs (Stensmyr et al., 2008), fungi, fruits, leaves, rotten cacti, compost heaps, slime flux (Ashburner, 1978; Markow and O'Grady, 2005), spider eggs (Titanochaetus) (Hardy, 1965), spittlebug fly larvae (Cladochaeta) (Grimaldi, 1999).

This seemingly endless diversity raises the question of how females from different species locate, recognize, and choose suitable oviposition substrates. In general, insects first localize their targets from a distance using long-range sensing (i.e., olfaction and vision). Olfactory cues can also stimulate egg laying when females are very close to the substrate. Finally, contact-based sensing (gustation and mechanosensation) completes the representation of the target as a possible oviposition substrate. With all this sensory information, females assess the quality of the substrate and decide to lay or not. Ideally, to understand how a female chooses where to lay an egg, one would like to identify all the different cues involved in oviposition site choice and determine how they are perceived through the different sensory modalities. Subsequently, one could then decipher how the various neural pathways sensing these cues are integrated with one another (and with internal states) to compose a representation of the quality of the substrate and, finally, decipher how this ultimately leads to a decision to lay an egg or not. A huge body of work has been accumulated on the various cues guiding oviposition behavior in many species over the past decades, however, only a handful of these insect species have been amenable to molecular or neuronal investigations. We will mostly focus here on species for which genetic or neuronal data are available, drawing parallels with other species when possible.

\section{Olfactory stimulation of egg-laying behavior}

Insects, like many other animals, use their sense of smell to locate a possible oviposition substrate from a distance. Some odors elicit oviposition, others inhibit it. We will focus our attention on the odors that modulate oviposition behavior specifically, although distinguishing odors that attract females because they signal an oviposition substrate from odors that stimulate oviposition over shorter distances can be challenging. A clear distinction between 
these two categories is sometimes only possible with the targeted functional manipulation of the odorant sensory neurons detecting these odors.

Phytophagous female insects often use the same host plant for feeding and for oviposition. This suggests that females may be equipped with a sex-specific olfactory neural pathway that detect the host plant as a possible oviposition substrate, while a distinct neural pathway that recognize the same plant as a food source might be shared by both sexes. In insects, odors are detected by olfactory sensory neurons, housed in sensilla located on the antenna and maxillary palps, which send their axonal projections to the antennal lobe, the first olfactory processing center of the brain. The antennal lobe is made of glomeruli, each receiving inputs from a sub-population of olfactory sensory neurons expressing the same type of olfactory receptor (OR) (Vosshall et al., 2000). At each glomerulus, olfactory sensory neurons connect with downstream projection neurons (PNs), which then convey the signals to higher brain centers, namely the mushroom body and lateral horn (Masse et al., 2009). Where in the olfactory system is the distinction between odors that signal an oviposition substrate and odors that indicate a food source encoded? Males and females of the hawkmoth Manduca sexta feed on the nectar of solanaceous flowers (Riffell et al., 2008), and females also use the solanaceous plants as oviposition substrates (Mechaber and Hildebrand, 2000). In this moth species, both feeding and oviposition behaviors are mediated primarily by olfactory cues (Ramaswamy, 1988; Sparks, 1970, 1973). One key floral scent involved in these two behaviors is linalool (Reisenman et al., 2010), which is produced in two chiral forms (or enantiomers), (+)-linalool and (-)-linalool, by hawkmoth-pollinated flowers. The linalool enantiomers mediate different behaviors in M. sexta: (+)-linalool elicits oviposition, while (-)linalool instead promotes feeding in both sexes (Reisenman et al., 2010). Remarkably, the $(+)$ - or (-)-linalool enantiomers activate preferentially different PNs in the female brain. PNs that respond selectively to antennal stimulation with $(+)$-linalool project to a female-specific glomerulus (Reisenman, 2004). By contrast, linalool-responsive PNs associated with sexually monomorphic glomeruli respond equally well to both enantiomers (Reisenman, 2004). This suggests that the two linalool enantiomers can modulate different behaviors through two distinct neural pathways, and that the neural circuit that responds to the oviposition-eliciting odor is female-specific.

More generally, different sets of plant-derived odors attract female moths for feeding or oviposition. Remarkably, the odorants eliciting feeding or oviposition activate different collections of olfactory glomeruli (Bisch-Knaden et al., 2018). These results indicate that moths do not rely on a single odor to locate an oviposition site, but can instead exploit several scents to guide them to a suitable substrate. They also suggest a model in which the various 
odors indicating oviposition substrates to a female are recognized by different olfactory receptors, expressed in distinct olfactory sensory neurons.

This model has been tested in D. melanogaster. Like most Drosophila species, D. melanogaster has a special relationship with fermenting or rotten substrates, in particular fruits. Flies are attracted by fruit odors and their olfactory system is tuned to the scent of the various metabolic compounds produced by the microorganisms growing on fruits, many of which mimic the scent of fruits ((Mansourian and Stensmyr, 2015) for review). Some of these odors also modulate oviposition behavior, positively or negatively, through dedicated olfactory sensory receptors and neurons. Ethanol and acetic acid, produced during the fermentation process, elicit egg laying (Adolph, 1920; Chen and Amrein, 2017; Joseph et al., 2009). In addition, oviposition is stimulated by the leaf odor E2-hexenal, detected by Or7a (Lin et al., 2015); by the volatile terpenes limonene and valencene, abundant in fruit of the Citrus family, detected by Or19a (Dweck et al., 2013); and by ethylphenols produced by yeast growing on fruit, detected by Or71a (Dweck et al., 2015). Of note, most of these oviposition-stimulating odors are otherwise not particularly attractive to females, suggesting instead that they specifically elicit oviposition when females are on, or very close to, the fruit. In parallel, females also detect olfactory cues that inhibit oviposition and which are produced by various threats that are common at or around oviposition sites. These deterrent odors include geosmin emanating from toxic molds, detected by Or56a (Stensmyr et al., 2012); phenol produced by pathogenic bacteria, detected by Or46a (Mansourian et al., 2016); and pheromones of parasitoid wasps, detected by Or49a (Ebrahim et al., 2015b). The activation of the olfactory sensory neurons expressing each of these receptors is sufficient to evoke, or inhibit, oviposition behavior, suggesting that these neurons and the odors they detect play key roles in the decision to lay an egg on a particular substrate. Most of the olfactory receptors involved in oviposition behavior are narrowly tuned (except Or7A, see below), and the olfactory sensory neurons expressing these receptors appear to be part of neural circuits that are dedicated to specific functions connected with egg-laying behavior. The specialization of these neural circuits to particular compounds contrasts with the combinatorial coding that is usually required to process odors. This uncommon situation could result from the strong ecological relevance of the signals detected by these circuits (Haverkamp et al., 2018).

In addition to olfactory cues emanating from the substrate itself, female D. melanogaster are also attracted and stimulated to lay eggs on particular spots by volatile pheromones deposited on the substrate by other individuals, males or females. Males deposit 9-tricosene, a cuticular hydrocarbon, in response to food odors, and this molecule is detected by Or7a in females and encourages females to lay eggs nearby (Lin et al., 2015). Mated females expel in their excreta 
the $\mathrm{cVA}$ that was transferred from males during copulation, which also acts as an aggregating pheromone for other mated females by marking high quality food (Sarin and Dukas, 2009; Wertheim et al., 2002). Mated females also deposit their own volatile, cuticular hydrocarbons that attract other females and stimulate oviposition (Duménil et al., 2016). Aggregating eggs in the same spot increases the local density of larvae, thereby maximizing the exploitation of the substrate (Dombrovski et al., 2017).

\section{Contribution of visual cues to oviposition site selection}

The visual system likely plays an essential role in the identification of suitable oviposition substrate for many insects. Some species that lay eggs in or nearby water sources, for instance midges (Lerner et al., 2008) or dragonflies (Horvath and Varju, 2004), use polarization of light reflected by the water surface to choose their oviposition substrate. Several Lepidoptera species use leaf shape (Rausher, 1978) or leaf color (Kelber, 1999) to target their favorite oviposition substrates. Mosquitoes also use water color and hues to choose an egg-laying site (Beehler et al., 1992; McCrae, 1984). D. melanogaster females can also discriminate egglaying substrates based on their color (Del Solar et al., 1974) and they avoid oviposition sites exposed to UV light (Zhu et al., 2014). This avoidance is mediated by UV-sensitive photoreceptors (Zhu et al., 2014), and also by UV-sensitive "bitter"-sensing neurons, located on the proboscis (Guntur et al., 2017).

As mentioned above, parasitoid wasp odors inhibit Drosophila egg-laying behavior.

Similarly, the visual detection of wasps is sufficient to alter female oviposition behavior: they actively search for a safe environment for their eggs, for instance a substrate containing high concentration of ethanol (Kacsoh et al., 2013), which protects the eggs from the wasps. Alternatively, if no suitable substrate is available, females retain their eggs and ultimately eliminate them. Females exposed to wasps can signal the danger to unexposed flies with wing movements: observers receiving this visual signal, although they have not seen the wasps themselves, will also retain and destroy their eggs (Kacsoh et al., 2015).

\section{Gustatory and contact-based assessment of oviposition substrates}

When females reach or land on a potential site for egg-laying, additional, contact-based cues become available. The stiffness and the texture of the substrate are assessed and contribute to the egg-laying decisions (Karageorgi et al., 2017; Rockwell and Grossfield, 1978), although not much is known about how this type of information is processed.

Females also evaluate the chemical composition of the substrate with their gustatory system. They probe the substrate with the various body parts equipped with chemosensory organs, 
mostly the legs, proboscis, and ovipositor. Although the role of some gustatory neurons located on the proboscis or the legs is well established (see below), the contribution of the ovipositor in oviposition site choice remains obscure in most species. The presence of chemosensory sensillae on the ovipositor of various species is indicated by the expression of chemoreceptor genes (odorant and gustatory receptors) (Glaser et al., 2013; Klinner et al., 2016) as well as the electrophysiological responses of some of these sensilla to various volatile or non-volatile molecules ((Klinner et al., 2016; Seada et al., 2016) and references therein; (Yadav and Borges, 2017)). For instance, four gustatory neurons types housed in sensilla on the ovipositor of the noctuid moth Spodoptera littoralis detect salt, caffeine, sugar, and water (Seada et al., 2016). The ovipositor of M. sexta is also covered with sensilla housing functional olfactory and gustatory sensory neurons (Klinner et al., 2016). In particular, some of these neurons express the gustatory receptors $(\mathrm{Gr})$ detecting $\mathrm{CO}_{2}$. The presence of chemosensory sensillae on the ovipositor can guide the search of concealed egglaying sites. This is illustrated with the oviposition behavior of the fig parasitoid wasp Apocrypta westwoodi, which insert their long, slender ovipositor into enclosed fig inflorescence, searching for pollinator wasp larvae, their favorite egg-laying site. The ovipositor of $A$. westwoodi detects and responds to $\mathrm{CO}_{2}$ emitted by these immobile larvae, guiding sensory probing inside the fruit (Yadav and Borges, 2017).

For most insect species, though, the oviposition substrates are not hidden and females can easily contact them and probe their chemical composition with their legs and proboscis, and sometimes antennae and ovipositor. In many butterfly species, females drum on the leaf surface, by rapidly alternating movement of their forelegs, before oviposition (Baur et al., 1998; Renou, 1983). Remarkably, this drumming behavior correlates with the presence on the foreleg tarsi of female-specific gustatory sensilla (Baur et al., 1998; Briscoe et al., 2013), and with the breadth of chemosensory receptor genes expressed specifically in female forelegs (Briscoe et al., 2013). These correlations suggest that females use drumming to taste oviposition stimulants and select their host plant.

This hypothesis has been tested in swallowtail butterflies. Papilionidae species use a limited number of plants in the Rutacea, Apiaceae or Lauraceae families, and each butterfly species requires a specific combination of chemicals from their host plant to lay eggs (Honda, 1990; Murakami, 2003). For instance Papilio xuthus requires a mixture of ten chemicals produced by citrus leaves, none of which on their own is sufficient to elicit oviposition (Ohsugi et al., 1991). One of these oviposition stimulant chemicals, synephrine, activates female-specific gustatory neurons housed in foreleg tarsi (Ryuda et al., 2013) and is sensed by a gustatory receptor, PxutGrl, expressed in female foreleg chemosensory neurons and required for the 
oviposition response to synephrine (Ozaki et al., 2011). Because synephrine acts as an oviposition stimulant only in combination with other chemicals, it will be important to identify the additional neurons and receptors that detect these compounds to better understand how a particular combination of chemical signals controls $P$. xuthus oviposition decision.

Insect species using water sources for oviposition can also face choices, for instance between freshwater and saltwater, especially for species or populations living in coastal areas. This is the case for many mosquito species, including Aedes aegypti. In this species, females lay their eggs on moist substrates near standing water, or just above the waterline (Hudson, 1956). Females, and their developing progeny, can tolerate salty water, but only up to a certain limit. A. aegypti females therefore avoid laying eggs near water sources containing high salt concentration (Matthews et al., 2018). Females assess salinity by touching the water surface with their legs and proboscis. Specifically, they rely on the DEG/ENaC channel ppk301 to detect suitable freshwater egg-laying sites. This channel is expressed in sensory neurons in the legs and the proboscis that respond both to salt and to water. Mosquitoes mutant for ppk301 channel are less stimulated to lay eggs near water, and are also less repelled by high salt concentrations, indicating that this channel plays a role in egg-laying site choice in $A$. aegypti (Matthews et al., 2018). Identifying whether the same neurons, or different subpopulations of ppk301-expressing neurons, respond to water and salt, will help to clarify how A. aegypti females choose an oviposition site between freshwater and saltwater.

D. melanogaster females also use gustatory cues to make oviposition decisions. As mentioned above, D. melanogaster sensory systems are tuned to many chemicals produced by fruit or during fermentation, some of which stimulate egg-laying behavior. For instance, females are stimulated to lay eggs when exposed to lobeline (Joseph and Heberlein, 2012), sugar (Schwartz et al., 2012; Yang et al., 2008; Yang et al., 2015a), acids (Chen and Amrein, 2017; Joseph et al., 2009), polyamines (Hussain et al., 2016), all of which are abundant in overripe or fermenting fruits. All these compounds are detected by different gustatory receptors or ionotropic receptors (IR), expressed in distinct subsets of gustatory neurons of the proboscis or the legs. Interestingly though, these chemical compounds have been shown to either elicit opposite behaviors, such as oviposition attraction and positional aversion, or to modulate oviposition preference in a context-dependent manner. Acetic acid, for instance, is aversive when it is detected by antennal olfactory sensory neurons, but acid detection by gustatory neurons of the forelegs stimulates egg-laying (Chen and Amrein, 2017; Joseph et al., 2009). Similarly, lobeline stimulates oviposition, but females avoid staying on it for too long (Joseph and Heberlein, 2012). In this case, the positional repulsion and oviposition stimulation is controlled by distinct sets of gustatory sensory neurons expressing the same gustatory 
receptor (Gr66) tuned to bitter compounds. A neuronal population of the leg dictates positional aversion, while a set of neurons in the internal mouthpart lining the pharynx stimulates oviposition (Joseph and Heberlein, 2012). In a converse manner, D. melanogaster females are strongly attracted to volatiles polyamines, but they avoid polyamine-rich agar oviposition substrates (Hussain et al., 2016). The preference is reversed, though, when polyamines are mixed with fruits: in this context females prefer to lay their eggs on polyamine-containing substrates (Hussain et al., 2016).

\section{Oviposition decisions are complex, context-dependent sensory choices}

In choosing precisely when and where to lay an egg, the nervous system of an animal must integrate internal drives with an evolutionarily defined look-up table of substrate preference. However, substrates can be complex, dynamic environments, and the decision circuits that regulate egg-laying behavior must factor in variables beyond the imminent oviposition site. These variables include the proximity of a site to suitable larval food sources and the presence of predators. This is reflected in oviposition behaviors and preferences that are heavily context-dependent. For instance, fermentation substrate (sugar), byproduct (alcohol) and actors (some strains of yeast and bacteria) are oviposition stimulants for D. melanogaster (Adolph, 1920; Becher et al., 2012; Yang et al., 2015a). However, the attraction to yeast, sugar and alcohol is dependent on the presence and the distance of an alternative oviposition site. D. melanogaster females prefer to oviposit on ethanol-containing substrates, but only as long as they are very close to an ethanol-free substrate (Sumethasorn and Turner, 2016). Symmetrically, they prefer to oviposit on sugar-free or yeast-free substrate, as long as substrates containing sugar or yeast are in close reach (Miller et al., 2011; Yang et al., 2008). The oviposition preference on sweet substrates is also influenced by the size of the arena, and therefore, presumably, by the frequency by which females encounter the sweet substrate (Schwartz et al., 2012). One possible interpretation to these observations is that females prefer to lay their eggs near a larval food source rather than on it because food can host pathogenic microorganisms, and attract predators and larval competitors. Furthermore, this 'proximity effect' suggests that females anticipate the foraging cost their progeny will face, and if the food source is too far from the oviposition site for the larvae to reach it, then females choose to lay their eggs directly on it. Importantly, these observations illustrate that the oviposition decision is not simply guided by the individual sensory inputs females perceive in their immediate environment. Rather, they suggest that females integrate a variety of parameters, assess and remember all available options and measure the distance separating them, and anticipate the consequences for her progeny before reaching a decision. 
Consistent this idea, there is mounting evidence in Drosophila that the egg-laying decision process is ultimately regulated by neurons and circuits classically associated with other forms of decision-making, learning and memory. Subsets of dopamine expressing neurons in the brain, specifically the SOG, PAL, and PPL2 clusters, have been implicated in the valuation of sugar content in potential egg-laying (Yang et al., 2015b). The assessment of ethanol concentration of a substrate, which can improve the fitness of the developing larvae by acting as both a food source and repellent of parasites, has also been tied to subsets of dopamine expressing neurons. High levels of ethanol can actually be detrimental to the development and survival of offspring and it has been suggested, interestingly, that distinct subsets of dopamine neurons encode either ethanol-favoring or ethanol-avoiding drive when multiple options are available (Azanchi et al., 2013). Furthermore, deciding between nearby substrate patches of different quality may be dependent on memory circuits previously implicated in olfactory conditioning, including the release of the amnesiac neuropeptide from the paired DPM neurons, and output from mushroom body $\alpha \beta$ neurons (Wu et al., 2015).

In addition to the modulation of particular oviposition cues, the nervous system must also integrate a variety of signals all at once to reach a behavioral decision. Several recent studies have started to examine where in the brain the integration of several olfactory signals directing oviposition decisions is taking place. All projection neurons immediately downstream of olfactory sensory neurons send their axons to the mushroom body calyx and the lateral horn, two brain centers crucial for associative learning, and innate odor responses, respectively (Marin et al., 2002). Strikingly, the innervation patterns of the projection neurons downstream of olfactory neurons detecting the aversive odors geosmin and iridomyrmecin overlap strongly and target the same regions of the mushroom body calyx and lateral horn (Ebrahim et al., 2015a; Huoviala et al., 2018). Furthermore, additional projection neurons downstream of olfactory sensory neurons involved in oviposition also send some axonal segments to the same ventral-posterior region of the lateral horn (Chin et al., 2018). Altogether, these results suggest that olfactory integration is taking place in this region of the lateral horn, where oviposition site selection, at least the component guided by olfactory cues, might be encoded. Whether or not a functionally analogous integration brain center exists for gustatory or visual cues involved in oviposition remains to be determined.

\section{HOW TO LAY AN EGG}

After a suitable site has been identified using both long- and short-range cues, the mated female must actuate the physical process of egg deposition. In general, this process entails an ordered sequence of behavioral motifs in which the animal contorts its abdomen to make 
contact with the substrate with a specialized egg-laying appendage, the ovipositor, and then undergoes a series of contractions resulting in the expulsion of an egg (Thompson, 1986; Yang et al., 2008). Eggs are deposited one at a time, with some insects laying a large clutch of eggs in a single site while others deposit just a single egg.

\section{Reproductive Anatomy}

This orderly sequence of external behaviors is paralleled by an internal sequence of processes by which mature eggs are shuttled through the internal reproductive system, fertilized and readied for deposition. Anatomically, the overall organization of the female reproductive system is conserved across insects (Demerec, 1950; Lange, 2009a). First, there is an egg factory, in the form of bilateral ovaries. These structures are the sites where germ cells mature into unfertilized eggs. Mature eggs are released from the ovaries into the lumen of a canal, the oviduct, where they start their journey towards the outside world. Each ovary feeds into its own oviduct, and these two lateral oviducts converge, forming a single common oviduct that ultimately leads to the genital chamber, or uterus. Only a single egg can be retained within the genital chamber, and it is here that fertilization occurs as sperm stored in attached sperm storage organs is released. Some insects have multiple sperm storage organs, three in the case of Drosophila (the seminal receptacle and two spermathecae), while others have a single organ (locusts, beetles). Additional secretions from a number of attached accessory glands release molecules that regulate ovulation (Sun and Spradling, 2013), or provide adhesion or protection to the expelled eggs (Thompson, 1986).

In the final stage of egg laying, eggs are expelled from the uterus and physically deposited in the environment via a highly specialized appendage, the ovipositor. This complex structure is made up of multiple ventral abdominal components originating from different segments (Grimaldi and Engel, 2005). In most winged insects (Pterygota), the shaft of the ovipositor combines different derivatives of the $8^{\text {th }}$ and $9^{\text {th }}$ ventral abdominal segments, organized in appressed bilateral structures and forming a tube or a guide. In contrast to the roughly conserved internal reproductive anatomy, the ovipositor exhibits dramatic diversification across the insect group, adapting to the particular demands of the substrate upon which eggs are laid. Yet, the ovipositor has retained at least one common element throughout insect evolution, a pair of bilateral plates derived from abdominal segment 9 , called gonocoxites (Grimaldi and Engel, 2005). From a mere guide to push the egg out, it has become in some species an organ to dig, to drill, or to navigate deep through wood cracks or fruits. The variety and versatility of ovipositors across Insecta is mirrored by the diversity in the number and type of sensory hairs across its surface (Ahmed et al., 2013; Belanger and Orchard, 1992; Zhang et al., 2012). 


\section{Motor Coordination}

The entirety of the female reproductive tract is highly muscularized, and these muscle systems are richly innervated by the neurites of sensory and motor neurons relaying signals to and from the central nervous system, more specifically the abdominal ganglia of the ventral nerve cord. The ventral nerve cord resides downstream of the head and is composed of multiple ganglia, roughly corresponding in number to the total number of body segments. In some cases, the ganglia are distributed as a chain across the length of the body (locusts), while in other insects the ganglia have become fused (flies) (Niven et al., 2008). Analogous to the vertebrate spinal cord, neural circuits of the ventral nerve cord regulate internal and external body functions, including vital functions such as circulation and digestion, as well as the generation of rhythmic behaviors such as flying or walking. Studies in locusts have revealed the presence of neural circuits known as central pattern generators (CPGs) within particular abdominal ganglia for multiple components of egg-laying behavior, including the opening and closing of the ovipositor valves during digging, the contraction of the oviducts during ovulation, as well as the release of sperm from storage during fertilization (Ayali and Lange, 2010; Silva and Lange, 2011; Thompson, 1986). These circuits are defined as CPGs because they are capable of generating rhythmic output autonomously, in the absence of patterned input (Marder et al., 2005). In fact, these rhythmic activity patterns were initially described in preparations where the relevant abdominal ganglia were isolated from descending inputs via nerve transection, which suggests that their expression is under inhibitory control from higher brain centers (Thompson, 1986).

Experiments, primarily in D. melanogaster and locusts, hint at generally conserved mechanisms in insects by which the central nervous system engages the muscles associated with egg laying. A prominently conserved feature in both animals is that reproductive muscle tissue is innervated by neurons that either release glutamate, the primary excitatory neurotransmitter at the invertebrate neuromuscular junction, or release OA, a biogenic amine (Lange, 2009a; Middleton et al., 2006; Monastirioti, 2003; Rodríguez-Valentín et al., 2006). $\mathrm{OA}$ is considered the invertebrate homolog to norepinephrine in mammals, given its closely related synthesis pathway, chemical structure and function (Roeder, 2005). Along these lines, OA has been implicated in priming the organism for action, for example by increasing the sensitivity of jump muscles in locusts (Walther and Zittlau, 1998), or by increasing the gain of visual interneurons during flight in Drosophila (Suver et al., 2012). Numerous studies have documented the diversity of effects that OA exerts on reproductive tissues, particularly on the oviduct. In both $D$. melanogaster and locusts, one function of $\mathrm{OA}$ is to inhibit oviduct contractions and muscle tonus via a cAMP-dependent mechanism linked to its binding to 
Oct $\beta$ receptors (Farooqui, 2012; Lange and Nykamp, 1996; Nykamp and Lange, 2000; Rodríguez-Valentín et al., 2006). Separately, in D. melanogaster, OA application increases contractile activity of the muscle sheath that wraps the ovaries (Rodríguez-Valentín et al., 2006), while in the cricket Gryllus bimaculatus, OA has also been demonstrated to increase the amplitude and frequency of myogenic, or muscle intrinsic, contractions of the oviduct (Tamashiro and Yoshino, 2014). In the extreme case, Drosophila mutants for OA production fail to expel eggs from the uterus, and this phenotype can be rescued by restoration of OA production in subsets of abdominal ganglion neurons (Monastirioti, 2003). Thus, as with other behaviors, OA release appears necessary to amplify the egg-laying capacity of the organism, particularly with regards to the progression of the egg. In contrast to these more modulatory affects, the impact of glutamate signaling is acute. This has been demonstrated in both locusts and fruit flies where glutamate induces immediate contraction of the oviduct, which in the locust results in egg retention (Gou et al., 2014; Lange et al., 1984). Taken together, it appears that these two neurotransmitter systems operate in parallel, with OA priming reproductive tissue to allow for the passage of eggs, while glutamatergic neurons mediate acute control from higher centers.

The execution of the component behaviors of egg laying is coordinated in part by sensory feedback from abdominal sensors, both internal and external, that convey the sensory state of the reproductive system and relevant appendages. Perhaps the most salient sensory stimulus for the coordination of egg-laying behaviors is the egg itself. For example, sensory neurons that detect the presence of an egg within the genital chamber have been implicated in the regulation of ovulation in the stick insect, by reflexively inducing constriction of the common oviduct (Thomas, 1979). Thus, this reflex circuit prevents ovulation until the egg is laid and the genital chamber is unoccupied. A similar circuit may coordinate fertilization, as experiments in the locust demonstrated that stimulation of the genital chamber by an eggshaped probe acutely increased motor input to and contractions of the spermathecal musculature (Clark and Lange, 2001). Beyond internally derived signals, central egg-laying circuits are modulated by feedback from external sensors, such as mechanosensory hairs that contact the substrate during oviposition. In the locust, there is evidence that afferent signaling from mechanosensory bristle neurons that line the ovipositor valves generates a reinforcing drive to the aforementioned digging CPG (Belanger and Orchard, 1992). Likewise, in the hawkmoth, cutting mechanosensory hairs on the anal papillae which normally maintain contact with the substrate during oviposition results in disorganized placement of eggs (Yamaoka et al., 1971).

\section{An Organizational Hierarchy}


The advanced genetic toolkit available in D. melanogaster has allowed for a more detailed description of the genes and neural circuits that regulate how eggs are laid. For one, there is overwhelming evidence that the gene $d s x$ plays an essential role in delineating the neural circuits that control female sexual behavior, including egg-laying behavior (Rideout et al., 2010). Silencing all $d s x$-positive neurons, as well as subsets that reside within the abdominal ganglion or those expressing OA, yields a complexity of reproduction-related deficits, including the reduction or even abolition of egg-laying behavior (Rezával et al., 2014; Rezával et al., 2012; Rideout et al., 2010). $d s x$ is also expressed in distinct clusters of sensory neurons throughout the lower reproductive tract, all of which are co-labelled by a reporter for Pickpocket, a DEG/ ENaC protein associated with proprioception. These neurons are thus poised to play critical roles in sensory feedback regarding the conformational state of the tract, particularly with regards to the position of the egg (Gou et al., 2014; Rezával et al., 2012).

Further studies of $d s x$-positive neurons out of the Yamamoto lab hint at the hierarchical organization of egg-laying motor circuits (Kimura et al., 2015). Activation of ventral nerve cord $d s x$-positive neurons could reliably induce components of egg-laying behavior, including abdominal bending and egg extrusion. This observation is consistent with those described in the locust in that it indicates that the circuits underlying the egg-laying motor pattern reside within the ventral nerve cord, though it is unclear from this study whether $d s x$-positive neurons merely activate or directly participate in these pattern generating circuits. Also, out of this work came the identification of female-specific $d s x$-positive descending interneurons, pMN2, whose activation was highly correlated with the induction of the sequence of oviposition behavior. Thus, pMN2 may represent command neurons that engage ventral nerve cord $d s x$-positive neurons for the induction of egg-laying. If true, deciphering the inputs to pMN2 will reveal critical insights into how the "when" and "where" aspects of egg-laying behavior are integrated to drive oviposition, meanwhile surveying the connections downstream of pMN2 within the ventral nerve cord will provide insight into the "how."

\section{PERSPECTIVES}

Overall, the decision and the process of laying an egg are governed by similar principles across insects, meanwhile the inputs shaping the decision and the context in which the behavior is expressed show extensive variation. The commonalities include: 1) a matingderived trigger that biases female behaviors towards those that favor the production of eggs and their deposition; 2) the integration of this mating status, plus other internal states such as the circadian clock, with sensory information about the environment; 3) a hierarchical system whereby dedicated neural circuits for the execution of egg-laying behavior reside within the 
ventral nerve cord and are under the control of higher brain centers (Fig. 1A). The variation, on the other hand, mirroring the diversity of niches and egg-laying substrates occupied by insects, is readily perceptible in the diversity of sensory cues used to guide oviposition across insects. This duality of conservation and variation leaves us with two broad categories of questions to fully understand when, where and how a female insect lays an egg.

First, critical links are missing regarding the relationship between sensory integration, decision-making and actuation. As we have seen, the decision rests on the integration of multiple parameters (sensory information, mating-state, circadian rhythms). How and where is this integration happening? Is there perhaps a neuron or small subset of command-like neurons in the brain that serve as master integrators? If true, how is the prioritization happening? Negative cues (signaling a threat or a danger), for instance, seem to overrule the positive signals stimulating oviposition. Likewise, some cues stimulate oviposition, but only in particular contexts. What is the neuronal organization that affords such ranking or contextbased rules?

Should there be a center in the brain that serves as the final gate for the decision to lay an egg, it remains possible that the integration of multiple sensory inputs is computed elsewhere, in centers like the mushroom body or lateral horn, with the processed output subsequently fed to the gate. To understand the underlying logic, it will be necessary to identify the components of the central nervous system involved in this processing and unravel their connectivity and function, for instance using the approach taken by (Huoviala et al., 2018). Likewise, to understand how the decision made by the brain is translated into the motor act of laying an egg, it is essential to clarify the circuit and functional architecture of the various CPGs associated with egg-laying, and to determine how they are engaged by descending neurons from the brain. Perhaps, as is the case with backwards crawling in Drosophila larvae, the circuit that links descending command-like neurons and premotor neurons is shallow, spanning only one or two synapses (Carreira-Rosario et al., 2018).

Second, the diversity of oviposition behaviors among insect species raises the question of how, from a neuronal perspective, has this behavior evolved. Are changes occurring in the input channels, in the central processing circuits, or in the motor pathways? As for variation in oviposition substrate choice, it is very likely that this results from changes in either the peripheral sensory system, or the circuit processing these inputs, or both. As species diverge to occupy new niches, it is important to develop heightened sensitivity to cues associated with new oviposition substrates. One strategy nature has taken towards this issue is by changing the sensitivity or number of sensory neurons detecting relevant cues (Fig. 1B). For instance, 
D. sechellia is particularly driven to lay eggs on Morinda citrifolia fruit because of their elevated hexanoic and octanoic acid concentration, which is otherwise toxic to other Drosophila species (Legal et al., 1999). This adaptation results, in part, from increased expression of two Odorant Binding Proteins in taste chemosensillae of the legs (Matsuo et al., 2007). In parallel, D. sechellia is also more attracted to volatile hexanoic acid as compared to other Drosophila species due to an increase in the number of acid-sensing olfactory sensory neurons, combined with the fine-tuning of the sensory receptor that detects this odor (PrietoGodino et al., 2017). In the same vein, the specialization of D. erecta on Pandanus spp. fruits correlates with an expansion of the population of olfactory sensory neurons that detect 3methyl-2-butenyl acetate, a fruit volatile compound that elicits oviposition in D. erecta (Linz et al., 2013).

Another mechanism that can enable diversification of behavior on evolutionary timescales relies not on peripheral changes but rather on the modification of how sensory inputs are processed centrally (Fig. 1C). Such a phenomenon has been observed in neural circuits that regulate courtship behavior between two closely related species, D. melanogaster and $D$. simulans, and serves as a mechanism that reinforces reproductive isolation between the two species (Seeholzer et al., 2018). Though the males of both species detect a pheromone specific to $D$. melanogaster females using homologous sensory neurons, whether the signal promotes (D. melanogaster) or suppresses (D. simulans) courtship is determined by speciesspecific alterations in the balance of excitation and inhibition in downstream relays onto the neurons that regulate courtship. Perhaps, as is the case here, more dramatic shifts in behavior with regards to a sensory cue, such as a change in valence from positive to negative, may invoke central modifications as opposed to peripheral ones.

Insect oviposition is a powerful paradigm to address fundamental questions about decisionmaking, multimodal integration and the evolution of behavior. Using modern technologies on a handful of models and their satellite species will both deepen our comprehension of the neural circuits that control an ecologically essential behavior, and reveal how and which variations in these circuits can produce the breadth of behavioral diversity we observe in insects.

Acknowledgments: B.P. acknowledges financial support from the European Research Council under the European Union's Seventh Framework Programme (FP/2007-2013) / ERC Grant Agreement $\mathrm{n}^{\circ} 615789$.

\section{REFERENCES}


Acebes, A., Cobb, M., Ferveur, J.F., 2003. Species-specific effects of single sensillum ablation on mating position in Drosophila. J Exp Biol 206, 3095-3100. Adolph, E.F., 1920. Egg-laying reactions in the pomace fly, Drosophila. Journal of Experimental Zoology 31, 326-341.

Ahmed, T., Zhang, T.-t., He, K.-l., Bai, S.-x., Wang, Z.-y., 2013. Sense organs on the ovipositor of Macrocentrus cingulum Brischke (Hymenoptera: Braconidae): their probable role in stinging, oviposition and host selection process. Journal of AsiaPacific Entomology 16, 343-348.

Allemand, R., 1974. Importance évolutive du comportement de ponte chez les insectes : comparaison du rythme circadien d'oviposition chez les six espèces de Drosophila du sous-groupe melanogaster. Comptes rendus hebdomadaires des séances de l'Académie des sciences. Série D 279, 2075-2077.

Allemand, R., 1976a. Les rythmes de vitellogenèse et d'ovulation en photoperiode LD 12:12 de Drosophila melanogaster. Journal of insect physiology 22, 1031-1035.

Allemand, R., 1976b. [Influence of light condition modification on the circadian rhythm of vitellogenesis and ovulation in Drosophila melanogaster]. Journal of insect physiology 22, 1075-1080.

Allemand, R., 1976c. Importance adaptative du rythme circadien de ponte chez les drosophilidés : comparaison de huit espèces du genre Zaprionus. Comptes rendus hebdomadaires des séances de l'Académie des sciences. Série D 282, 8588.

Allemand, R., 1977. Influence de l'intensité d'éclairement sur l'expression du rythme journalier d'oviposition de Drosophila melanogaster en condtions lumineuses. Comptes rendus hebdomadaires des séances de l'Académie des sciences. Série D 284, 1553-1556.

Ameku, T., Niwa, R., 2016. Mating-Induced Increase in Germline Stem Cells via the Neuroendocrine System in Female Drosophila. PLoS genetics 12, e1006123. Arthur, B.I., Jr., Jallon, J.M., Caflisch, B., Choffat, Y., Nothiger, R., 1998. Sexual behaviour in Drosophila is irreversibly programmed during a critical period. Curr Biol 8, 1187-1190.

Ashburner, M., 1978. The Genetics and Biology of Drosophila.

Ayali, A., Lange, A.B., 2010. Rhythmic behaviour and pattern-generating circuits in the locust: Key concepts and recent updates. Journal of Insect Physiology 56, 834-843.

Azanchi, R., Kaun, K.R., Heberlein, U., 2013. Competing dopamine neurons drive oviposition choice for ethanol in Drosophila. Proc Natl Acad Sci U S A 110, 21153-21158.

Baur, R., Haribal, M., Renwick, J.A.A., Stadler, E., 1998. Contact chemoreception related to host selection and oviposition behaviour in the monarch butterfly, Danaus plexippus. Physiological Entomology 23, 7-19.

Becher, P.G., Flick, G., Rozpędowska, E., Schmidt, A., Hagman, A., Lebreton, S., Larsson, M.C., Hansson, B.S., Piškur, J., Witzgall, P., Bengtsson, M., 2012. Yeast, not fruit volatiles mediate Drosophila melanogaster attraction, oviposition and development. Functional Ecology 26, 822-828.

Beehler, J., Lohr, S., DeFoliart, G., 1992. Factors Influencing Oviposition in Aedes Triseriatus (Diptera: Culicidae). 25, 7. 
Belanger, J.H., Orchard, I., 1992. The role of sensory input in maintaining output from the locust oviposition digging central pattern generator. Journal of Comparative Physiology A 171, 495-503.

Bisch-Knaden, S., Dahake, A., Sachse, S., Knaden, M., Hansson, B.S., 2018. Spatial Representation of Feeding and Oviposition Odors in the Brain of a Hawkmoth. Cell Reports 22, 2482-2492.

Bono, J.M., Matzkin, L.M., Kelleher, E.S., Markow, T.A., 2011. Postmating transcriptional changes in reproductive tracts of con- and heterospecifically mated Drosophila mojavensis females. Proc Natl Acad Sci U S A 108, 7878-7883. Brady, J., 1974. The physiology of insect circadian rhythms. Advances in Insect Physiology, 1-115.

Brieger, G., Butterworth, F.M., 1970. Drosophila melanogaster: identity of male lipid in reproductive system. Science 167, 1262.

Briscoe, A.D., Macias-Muñoz, A., Kozak, K.M., Walters, J.R., Yuan, F., Jamie, G.A., Martin, S.H., Dasmahapatra, K.K., Ferguson, L.C., Mallet, J., Jacquin-Joly, E., Jiggins, C.D., 2013. Female Behaviour Drives Expression and Evolution of Gustatory Receptors in Butterflies. PLoS Genetics 9, e1003620.

Carreira-Rosario, A., Zarin, A.A., Clark, M.Q., Manning, L., Fetter, R.D., Cardona, A., Doe, C.Q., 2018. MDN brain descending neurons coordinately activate backward and inhibit forward locomotion. Elife 7.

Carson, H.L., Kaneshiro, K.Y., 1976. Drosophila of Hawaii: Systematics and Ecological Genetics. Annual Review of Ecology and Systematics 7, 311-345.

Carvalho, G.B., Kapahi, P., Anderson, D.J., Benzer, S., 2006. Allocrine modulation of feeding behavior by the Sex Peptide of Drosophila. Curr Biol 16, 692-696.

Chen, P.S., Stumm-Zollinger, E., Aigaki, T., Balmer, J., Bienz, M., Bohlen, P., 1988. A male accessory gland peptide that regulates reproductive behavior of female $D$. melanogaster. Cell 54, 291-298.

Chen, Y., Amrein, H., 2017. Ionotropic Receptors Mediate Drosophila Oviposition Preference through Sour Gustatory Receptor Neurons. Curr Biol 27, 2741-2750 e2744.

Chin, S.G., Maguire, S.E., Huoviala, P., Jefferis, G., Potter, C.J., 2018. Olfactory Neurons and Brain Centers Directing Oviposition Decisions in Drosophila. Cell Rep 24, 1667-1678.

Clark, J., Lange, A.B., 2001. Evidence of a neural loop involved in controlling spermathecal contractions in Locusta migratoria. Journal of Insect Physiology 47, 607-616.

Del Solar, E., Guijón, A.M., Walker, L., 1974. Choice of colored substrates for oviposition in Drosophila melanogaster. Bolletino de Zoologia 41, 253-260. Delbare, S.Y.N., Chow, C.Y., Wolfner, M.F., Clark, A.G., 2017. Roles of Female and Male Genotype in Post-Mating Responses in Drosophila melanogaster. J Hered 108, 740-753.

Delisle, J., Picimbon, J., Simard, J., 2000. Regulation of pheromone inhibition in mated females of Choristoneura fumiferana and C. rosaceana. Journal of insect physiology 46, 913-921.

Demerec, M., 1950. Biology of Drosophila. John Wiley and Sons.

Dombrovski, M., Poussard, L., Moalem, K., Kmecova, L., Hogan, N., Schott, E., Vaccari, A., Acton, S., Condron, B., 2017. Cooperative Behavior Emerges among Drosophila Larvae. Current biology: CB 27, 2821-2826.e2822. 
Duménil, C., Woud, D., Pinto, F., Alkema, J.T., Jansen, I., Van Der Geest, A.M., Roessingh, S., Billeter, J.-C., 2016. Pheromonal Cues Deposited by Mated Females Convey Social Information about Egg-Laying Sites in Drosophila Melanogaster. Journal of Chemical Ecology 42, 259-269.

Dweck, Hany K.M., Ebrahim, Shimaa A.M., Farhan, A., Hansson, Bill S., Stensmyr, Marcus C., 2015. Olfactory Proxy Detection of Dietary Antioxidants in Drosophila. Current Biology 25, 455-466.

Dweck, H.K.M., Ebrahim, S.A.M., Kromann, S., Bown, D., Hillbur, Y., Sachse, S., Hansson, B.S., Stensmyr, M.C., 2013. Olfactory Preference for Egg Laying on Citrus Substrates in Drosophila. Current biology : CB, 1-9.

Ebrahim, S.A., Dweck, H.K., Stokl, J., Hofferberth, J.E., Trona, F., Weniger, K., Rybak, J., Seki, Y., Stensmyr, M.C., Sachse, S., Hansson, B.S., Knaden, M., 2015a. Drosophila Avoids Parasitoids by Sensing Their Semiochemicals via a Dedicated Olfactory Circuit. PLoS Biol 13, e1002318.

Ebrahim, S.A.M., Dweck, H.K.M., Stökl, J., Hofferberth, J.E., Trona, F., Weniger, K., Rybak, J., Seki, Y., Stensmyr, M.C., Sachse, S., Hansson, B.S., Knaden, M., 2015b. Drosophila Avoids Parasitoids by Sensing Their Semiochemicals via a Dedicated Olfactory Circuit. PLOS Biology 13, e1002318.

Farooqui, T., 2012. Review of octopamine in insect nervous systems. Open Access Insect Physiology 4, 1-17.

Feng, K., Palfreyman, M.T., Hasemeyer, M., Talsma, A., Dickson, B.J., 2014.

Ascending SAG neurons control sexual receptivity of Drosophila females. Neuron 83, 135-148.

Ferguson, C.T., O'Neill, T.L., Audsley, N., Isaac, R.E., 2015. The sexually dimorphic behaviour of adult Drosophila suzukii: elevated female locomotor activity and loss of siesta is a post-mating response. J Exp Biol 218, 3855-3861.

Findlay, G.D., Yi, X., Maccoss, M.J., Swanson, W.J., 2008. Proteomics reveals novel

Drosophila seminal fluid proteins transferred at mating. PLoS Biol 6, e178.

Gabrieli, P., Kakani, E.G., Mitchell, S.N., Mameli, E., Want, E.J., Mariezcurrena Anton, A., Serrao, A., Baldini, F., Catteruccia, F., 2014. Sexual transfer of the steroid hormone 20E induces the postmating switch in Anopheles gambiae. Proc Natl Acad Sci U S A 111, 16353-16358.

Gillott, C., 2003. Male accessory gland secretions: modulators of female reproductive physiology and behavior. Annual review of entomology 48, 163184.

Glaser, N., Gallot, A., Legeai, F., Montagné, N., Poivet, E., Harry, M., Calatayud, P.-A., Jacquin-Joly, E., 2013. Candidate Chemosensory Genes in the Stemborer Sesamia nonagrioides. International Journal of Biological Sciences 9, 481-495.

Gomulski, L.M., Dimopoulos, G., Xi, Z., Scolari, F., Gabrieli, P., Siciliano, P., Clarke, A.R., Malacrida, A.R., Gasperi, G., 2012. Transcriptome profiling of sexual maturation and mating in the Mediterranean fruit fly, Ceratitis capitata. PLoS ONE 7, e30857.

Gou, B., Liu, Y., Guntur, A.R., Stern, U., Yang, C.-h., 2014. Mechanosensitive neurons on the internal reproductive tract contribute to egg-laying-induced acetic acid attraction in Drosophila. Cell Reports 9, 522-530.

Grimaldi, D., Engel, M.S., 2005. Evolution of the Insects, 1st Edition ed. Cambridge University Press.

Grimaldi, D.A., 1999. Monograph on the spittlebug flies, genus Cladochaeta (Diptera, Drosophilidae, Cladochaetini). Bull. AMNH 241, 1-326. 
Guntur, A.R., Gou, B., Gu, P., He, R., Stern, U., Xiang, Y., Yang, C.H., 2017. H2O2Sensitive Isoforms of Drosophila melanogaster TRPA1 Act in Bitter-Sensing Gustatory Neurons to Promote Avoidance of UV During Egg-Laying. Genetics 205, 749-759.

Hardy, E., 1965. Series Schizophora, Section Acalypterae I, Family Drosophilidae. University of Hawaii Press, Honolulu.

Hasemeyer, M., Yapici, N., Heberlein, U., Dickson, B.J., 2009. Sensory Neurons in the Drosophila Genital Tract Regulate Female Reproductive Behavior. Neuron 61, 511-518.

Haverkamp, A., Hansson, B.S., Knaden, M., 2018. Combinatorial Codes and Labeled Lines: How Insects Use Olfactory Cues to Find and Judge Food, Mates, and Oviposition Sites in Complex Environments. Front Physiol 9, 49.

Heifetz, Y., Lung, O., Frongillo, E.A., Jr., Wolfner, M.F., 2000. The Drosophila seminal fluid protein Acp26Aa stimulates release of oocytes by the ovary. Curr Biol 10, 99-102.

Honda, K., 1990. Identification of host-plant chemicals stimulating oviposition by swallowtail butterfly,Papilio protenor. Journal of Chemical Ecology 16, 325-337. Horvath, G., Varju, D., 2004. Polarized Light in Animal Vision: Polarization Patterns in Nature. Springer Verlag, Berlin.

Hudson, B.N.A., 1956. The Behaviour of the Female Mosquito in Selecting Water for Oviposition. Journal of Experimental Biology 33, 478.

Huoviala, P., Dolan, M.-J., Love, F., Frechter, S., Roberts, R.J.V., Mitrevica, Z., Schlegel, P., Bates, A.S.S., Aso, Y., Rodrigues, T., Cornwall, H., Stensmyr, M., Bock, D., Rubin, G.M., Costa, M., Jefferis, G.S.X.E., 2018. Neural circuit basis of aversive odour processing in Drosophila from sensory input to descending output. BioRxiv.

Hussain, A., Ucpunar, H.K., Zhang, M., Loschek, L.F., Grunwald Kadow, I.C., 2016. Neuropeptides Modulate Female Chemosensory Processing upon Mating in Drosophila. PLoS Biol 14, e1002455.

Joseph, R.M., Devineni, A.V., King, I.F., Heberlein, U., 2009. Oviposition preference for and positional avoidance of acetic acid provide a model for competing behavioral drives in Drosophila. Proc Natl Acad Sci U S A 106, 11352-11357. Joseph, R.M., Heberlein, U., 2012. Tissue-specific activation of a single gustatory receptor produces opposing behavioral responses in Drosophila. Genetics 192, 521-532.

Kacsoh, B.Z., Bozler, J., Ramaswami, M., Bosco, G., 2015. Social communication of predator-induced changes in Drosophila behavior and germ line physiology. eLife 4.

Kacsoh, B.Z., Lynch, Z.R., Mortimer, N.T., Schlenke, T.A., 2013. Fruit Flies Medicate Offspring After Seeing Parasites. Science 339, 947-950.

Kambysellis, M.P., Heed, W.B., 1971. Studies of Oogenesis in Natural Populations of Drosophilidae. I. Relation of Ovarian Development and Ecological Habitats of the Hawaiian Species. The American naturalist 105, 31-49.

Karageorgi, M., Bracker, L.B., Lebreton, S., Minervino, C., Cavey, M., Siju, K.P., Grunwald Kadow, I.C., Gompel, N., Prud'homme, B., 2017. Evolution of Multiple Sensory Systems Drives Novel Egg-Laying Behavior in the Fruit Pest Drosophila suzukii. Curr Biol 27, 847-853.

Kelber, A., 1999. Ovipositing butterflies use a red receptor to see green. Journal of Experimental Biology 202, 2619-2630. 
Kelleher, E.S., Watts, T.D., LaFlamme, B.A., Haynes, P.A., Markow, T.A., 2009. Proteomic analysis of Drosophila mojavensis male accessory glands suggests novel classes of seminal fluid proteins. Insect Biochem Mol Biol 39, 366-371. Kim, Y.J., Bartalska, K., Audsley, N., Yamanaka, N., Yapici, N., Lee, J.Y., Kim, Y.C., Markovic, M., Isaac, E., Tanaka, Y., Dickson, B.J., 2010. MIPs are ancestral ligands for the sex peptide receptor. Proc Natl Acad Sci U S A 107, 6520-6525. Kimura, K.-i., Sato, C., Koganezawa, M., Yamamoto, D., 2015. Drosophila Ovipositor Extension in Mating Behavior and Egg Deposition Involves Distinct Sets of Brain Interneurons. PLOS ONE 10, e0126445.

Klinner, C.F., König, C., Missbach, C., Werckenthin, A., Daly, K.C., Bisch-Knaden, S., Stengl, M., Hansson, B.S., Große-Wilde, E., 2016. Functional Olfactory Sensory Neurons Housed in Olfactory Sensilla on the Ovipositor of the Hawkmoth Manduca sexta. Frontiers in Ecology and Evolution 4.Lange, A.B., 2009b. Neural mechanisms coordinating the female reproductive system in the locust. Frontiers in Bioscience Volume, 4401.

Lange, A.B., Nykamp, D.A., 1996. Signal transduction pathways regulating the contraction of an insect visceral muscle. Archives of Insect Biochemistry and Physiology 33, 183-196.

Lange, A.B., Orchard, I., Loughton, B.G., 1984. Neural inhibition of egg-laying in the locust, Locusta migratoria. Journal of Insect Physiology 30, 271-278.

Legal, L., Moulin, B., Jallon, J.M., 1999. The Relation between Structures and Toxicity of Oxygenated Aliphatic Compounds Homologous to the Insecticide Octanoic Acid and the Chemotaxis of Two Species of Drosophila. Pesticide Biochemistry and Physiology 65, 90-101.

Lenschow, M., Cordel, M., Pokorny, T., Mair, M.M., Hofferberth, J., Ruther, J., 2018. The Post-mating Switch in the Pheromone Response of Nasonia Females Is Mediated by Dopamine and Can Be Reversed by Appetitive Learning. Frontiers in behavioral neuroscience 12, 14.

Lerner, A., Meltser, N., Sapir, N., Erlick, C., Shashar, N., Broza, M., 2008. Reflected polarization guides chironomid females to oviposition sites. Journal of Experimental Biology 211, 3536-3543.

Lin, C.-C., Prokop-Prigge, K.A., Preti, G., Potter, C.J., 2015. Food odors trigger Drosophila males to deposit a pheromone that guides aggregation and female oviposition decisions. eLife 4.

Linz, J., Baschwitz, A., Strutz, A., Dweck, H.K.M., Sachse, S., Hansson, B.S., Stensmyr, M.C., 2013. Host plant-driven sensory specialization in Drosophila erecta. Proceedings of the Royal Society B: Biological Sciences 280, 20130626. Mack, P.D., Kapelnikov, A., Heifetz, Y., Bender, M., 2006. Mating-responsive genes in reproductive tissues of female Drosophila melanogaster. Proc Natl Acad Sci U S A 103, 10358-10363.

Manjunatha, T., Hari Dass, S., Sharma, V.K., 2008. Egg-laying rhythm in Drosophila melanogaster. Journal of Genetics 87, 495-504.

Mansourian, S., Corcoran, J., Enjin, A., Löfstedt, C., Dacke, M., Stensmyr, Marcus C., 2016. Fecal-Derived Phenol Induces Egg-Laying Aversion in Drosophila. Current Biology 26, 2762-2769.

Mansourian, S., Stensmyr, M.C., 2015. The chemical ecology of the fly. Current Opinion in Neurobiology 34, 95-102.

Marder, E., Bucher, D., Schulz, D.J., Taylor, A.L., 2005. Invertebrate Central Pattern Generation Moves along. Current Biology 15, R685-R699. 
Marin, E.C., Jefferis, G.S.X.E., Komiyama, T., Zhu, H., Luo, L., 2002. Representation of the glomerular olfactory map in the Drosophila brain. Cell 109, 243-255.

Markow, T.A., O'Grady, P.M., 2005. Drosophila - A Guide to Species Identification and Use. Academic Press.

Masse, N.Y., Turner, G.C., Jefferis, G.S.X.E., 2009. Olfactory information processing in Drosophila. Current biology: CB 19, R700-713.

Matsuo, T., Sugaya, S., Yasukawa, J., Aigaki, T., Fuyama, Y., 2007. Odorant-Binding Proteins 0BP57d and 0BP57e Affect Taste Perception and Host-Plant Preference in Drosophila sechellia. PLoS Biology 5, e118.

Matthews, B.J., Younger, M.A., Vosshall, L.B., 2018. The ion channel ppk301 controls freshwater egg-laying in the mosquito Aedes aegypti. BioRxiv.

McCrae, A.W., 1984. Oviposition by African malaria vector mosquitoes. II. Effects of site tone, water type and conspecific immatures on target selection by

freshwater Anopheles gambiae Giles, sensu lato. Annals of Tropical Medicine and Parasitology 78, 307-318.

McGraw, L.A., Clark, A.G., Wolfner, M.F., 2008. Post-mating gene expression profiles of female Drosophila melanogaster in response to time and to four male accessory gland proteins. Genetics 179, 1395-1408.

Mechaber, W.L., Hildebrand, J.G., 2000. Novel, Non-Solanaceous Hostplant Record for Manduca sexta (Lepidoptera: Sphingidae) in the Southwestern United States. Annals of the Entomological Society of America 93, 447-451.

Middleton, C.A., Nongthomba, U., Parry, K., Sweeney, S.T., Sparrow, J.C., Elliott, C.J.H., 2006. Neuromuscular organization and aminergic modulation of contractions in the Drosophila ovary. BMC biology 4, 17.

Miller, P.M., Saltz, J.B., Cochrane, V.A., Marcinkowski, C.M., Mobin, R., Turner, T.L., 2011. Natural variation in decision-making behavior in Drosophila melanogaster. PLoS One 6, e16436.

Monastirioti, M., 2003. Distinct octopamine cell population residing in the CNS abdominal ganglion controls ovulation in Drosophila melanogaster.

Developmental Biology 264, 38-49.

Murakami, T., 2003. Studies on the relationships between host-plant acceptability and plant constituents in host selection by a swallowtail butterfly, Papilio polytes.

Niven, J.E., Graham, C.M., Burrows, M., 2008. Diversity and Evolution of the Insect Ventral Nerve Cord. Entomology 53, 253-271.

Nykamp, D.A., Lange, A.B., 2000. Interaction between octopamine and proctolin on the oviducts of Locusta migratoria. Journal of Insect Physiology 46, 809-816. Ohsugi, T., Nishida, R., Fukami, H., 1991. Multi-Component System of Oviposition Stimulants for a Rutaceae-Feeding Swallowtail Butterfly, Papilio xuthus(Lepidoptera:Papilionidae). Applied Entomology and Zoology 26, 29-40. Ozaki, K., Ryuda, M., Yamada, A., Utoguchi, A., Ishimoto, H., Calas, D., Marion-Poll, F., Tanimura, T., Yoshikawa, H., 2011. A gustatory receptor involved in host plant recognition for oviposition of a swallowtail butterfly. Nature communications 2 , 542.

Peng, J., Chen, S., Busser, S., Liu, H., Honegger, T., Kubli, E., 2005. Gradual release of sperm bound sex-peptide controls female postmating behavior in Drosophila. Curr Biol 15, 207-213. 
Prieto-Godino, L.L., Rytz, R., Cruchet, S., Bargeton, B., Abuin, L., Silbering, A.F., Ruta, V., Dal Peraro, M., Benton, R., 2017. Evolution of Acid-Sensing Olfactory Circuits in Drosophilids. Neuron 93, 661-676.e666.

Ram, K.R., Wolfner, M.F., 2007. Sustained post-mating response in Drosophila melanogaster requires multiple seminal fluid proteins. PLoS Genet 3, e238.

Ramaswamy, S.B., 1988. Host finding by moths: Sensory modalities and behaviours. Journal of Insect Physiology 34, 235-249.

Rausher, M.D., 1978. Search image for leaf shape in a butterfly. Science (New York, N.Y.) 200, 1071-1073.

Reisenman, C.E., 2004. Enantioselectivity of Projection Neurons Innervating Identified Olfactory Glomeruli. Journal of Neuroscience 24, 2602-2611.

Reisenman, C.E., Riffell, J.A., Bernays, E.A., Hildebrand, J.G., 2010. Antagonistic effects of floral scent in an insect-plant interaction. Proceedings of the Royal Society B: Biological Sciences 277, 2371-2379.

Renou, M., 1983. Les récepteurs gustatifs du tarse antérieur de la femelle d'Heliconius charitonius (Lep.: Heliconiidae). Annls Soc Ent Fr (NS) 19, 101-106. Rezaval, C., Nojima, T., Neville, M.C., Lin, A.C., Goodwin, S.F., 2014. Sexually dimorphic octopaminergic neurons modulate female postmating behaviors in Drosophila. Curr Biol 24, 725-730.

Rezával, C., Pavlou, Hania J., Dornan, Anthony J., Chan, Y.-B., Kravitz, Edward A., Goodwin, Stephen F., 2012. Neural Circuitry Underlying Drosophila Female Postmating Behavioral Responses. Current Biology 22, 1155-1165.

Rezaval, C., Pavlou, H.J., Dornan, A.J., Chan, Y.B., Kravitz, E.A., Goodwin, S.F., 2012. Neural circuitry underlying Drosophila female postmating behavioral responses. Curr Biol 22, 1155-1165.

Rideout, E.J., Dornan, A.J., Neville, M.C., Eadie, S., Goodwin, S.F., 2010. Control of sexual differentiation and behavior by the doublesex gene in Drosophila melanogaster. Nature Neuroscience 13, 458.

Riffell, J.A., Alarcon, R., Abrell, L., Davidowitz, G., Bronstein, J.L., Hildebrand, J.G., 2008. Behavioral consequences of innate preferences and olfactory learning in hawkmoth-flower interactions. Proceedings of the National Academy of Sciences 105, 3404-3409.

Rockwell, R.F., Grossfield, J., 1978. Drosophila: Behavioral Cues for Oviposition. American Midland Naturalist 99, 361-368.

Rodríguez-Valentín, R., López-González, I., Jorquera, R., Labarca, P., Zurita, M., Reynaud, E., 2006. Oviduct contraction in Drosophila is modulated by a neural network that is both, octopaminergic and glutamatergic. Journal of cellular physiology 209, 183-198.

Roeder, T., 2005. Tyramine and octopamine: ruling behavior and metabolism. Annual review of entomology 50, 447-477.

Ryuda, M., Calas-List, D., Yamada, A., Marion-Poll, F., Yoshikawa, H., Tanimura, T., Ozaki, K., 2013. Gustatory Sensing Mechanism Coding for Multiple Oviposition Stimulants in the Swallowtail Butterfly, Papilio Xuthus. Journal of Neuroscience 33, 914-924.

Sarin, S., Dukas, R., 2009. Social learning about egg-laying substrates in fruitflies. Proceedings. Biological Sciences 276, 4323-4328.

Schwartz, N.U., Zhong, L., Bellemer, A., Tracey, W.D., 2012. Egg laying decisions in Drosophila are consistent with foraging costs of larval progeny. PLoS One 7, e37910. 
Seada, M.A., Ignell, R., Anderson, P., 2016. Morphology and distribution of ovipositor sensilla of female cotton leaf worm $S$ podoptera littoralis (Lepidoptera: Noctuidae), and evidence for gustatory function: Spodoptera ovipositor sensilla. Entomological Science 19, 9-19.

Seeholzer, L.F., Seppo, M., Stern, D.L., Ruta, V., 2018. Evolution of a central neural circuit underlies Drosophila mate preferences. Nature 559, 564-569.

Sheeba, V., Chandrashekaran, M.K., Joshi, A., Sharma, V.K., 2001. Persistence of oviposition rhythm in individuals of Drosophila melanogaster reared in an aperiodic environment for several hundred generations. The Journal of experimental zoology 290, 541-549.

Silva, R.d., Lange, A.B., 2011. Evidence of a central pattern generator regulating spermathecal muscle activity in Locusta migratoria and its coordination with oviposition. Journal of Experimental Biology 214, 757-763.

Sitnik, J.L., Gligorov, D., Maeda, R.K., Karch, F., Wolfner, M.F., 2016. The Female Post-Mating Response Requires Genes Expressed in the Secondary Cells of the Male Accessory Gland in Drosophila melanogaster. Genetics 202, 1029-1041. Snodgrass, R.E., 1935. Principles of Insect Morphology. McGraw-Hill Book Company.

Soller, M., Bownes, M., Kubli, E., 1999. Control of oocyte maturation in sexually mature Drosophila females. Dev Biol 208, 337-351.

Sparks, M.R., 1970. A Surrogate Leaf for Oviposition by the Tobacco Hornworm12. Journal of Economic Entomology 63, 537-540.

Sparks, M.R., 1973. Physical and Chemical Stimuli Affecting Oviposition Preference of Manduca sexta (Lepidoptera: Sphingidae). Annals of the Entomological Society of America 66, 571-573.

Stensmyr, M.C., Dweck, H.K., Farhan, A., Ibba, I., Strutz, A., Mukunda, L., Linz, J., Grabe, V., Steck, K., Lavista-Llanos, S., Wicher, D., Sachse, S., Knaden, M., Becher, P.G., Seki, Y., Hansson, B.S., 2012. A conserved dedicated olfactory circuit for detecting harmful microbes in Drosophila. Cell 151, 1345-1357.

Stensmyr, M.C., Stieber, R., Hansson, B.S., 2008. The Cayman crab fly revisited-phylogeny and biology of Drosophila endobranchia. PLoS ONE 3, e1942.

Sumethasorn, M., Turner, T.L., 2016. Oviposition preferences for ethanol depend on spatial arrangement and differ dramatically among closely related Drosophila species. Biology Open 5, 1642-1647.

Sun, J., Spradling, A.C., 2013. Ovulation in Drosophila is controlled by secretory cells of the female reproductive tract. eLife 2, e00415.

Suver, M.P., Mamiya, A., Dickinson, M.H., 2012. Octopamine neurons mediate flight-induced modulation of visual processing in Drosophila. Curr Biol 22, 22942302.

Tamashiro, H., Yoshino, M., 2014. Signaling pathway underlying the octopaminergic modulation of myogenic contraction in the cricket lateral oviduct. J Insect Physiol 71, 30-36.

Taylor, B.J., 1989. Sexually dimorphic neurons of the terminalia of Drosophila melanogaster: II. Sex-specific axonal arborizations in the central nervous system. J Neurogenet 5, 193-213.

Thomas, A., 1979. Nervous control of egg progression into the common oviduct and genital chamber of the stick-insect Carausius morosus. Journal of Insect Physiology 25, 811-823. 
Thompson, K.J., 1986. Oviposition digging in the grasshopper. II. Descending neural control. The Journal of experimental biology 122, 413-425.

von Helversen, D., von Helversen, O., 1991. Pre-mating sperm removal in the bushcricket Metaplastes ornatus Ramme 1931 (Orthoptera, Tettigonoidea, Phaneropteridae). Behavioral Ecology and Sociobiology 28, 391-396.

Vosshall, L.B., Wong, A.M., Axel, R., 2000. An olfactory sensory map in the fly brain. Cell 102, 147-159.

Walther, C., Zittlau, K.E., 1998. Resting membrane properties of locust muscle and their modulation II. Actions of the biogenic amine octopamine. J

Neurophysiol 80, 785-797.

Wertheim, B., Dicke, M., Vet, L.E.M., 2002. Behavioural plasticity in support of a benefit for aggregation pheromone use in Drosophila melanogaster. Entomologia Experimentalis et Applicata 103, 61-71.

Wu, C.-L., Fu, T.-F., Chou, Y.-Y., Yeh, S.-R., 2015. A Single Pair of Neurons

Modulates Egg-Laying Decisions in Drosophila. PLOS ONE 10, e0121335.

Yadav, P., Borges, R.M., 2017. The insect ovipositor as a volatile sensor within a closed microcosm. Journal of Experimental Biology 220, 1554-1557.

Yamaoka, K., Hoshino, M., Hirao, T., 1971. Role of sensory hairs on the anal papillae in oviposition behaviour of Bombyx mori. Journal of Insect Physiology 17, 897-911.

Yang, C.-h., Belawat, P., Hafen, E., Jan, L.Y., Jan, Y.-N., 2008. Drosophila egg-laying site selection as a system to study simple decision-making processes. Science (New York, NY) 319, 1679-1683.

Yang, C.-H., He, R., Stern, U., 2015a. Behavioral and Circuit Basis of Sucrose Rejection by Drosophila Females in a Simple Decision-Making Task. Journal of Neuroscience 35, 1396-1410.

Yang, C.-h., Rumpf, S., Xiang, Y., Gordon, M.D., Song, W., Jan, L.Y., Jan, Y.-N., 2009a. Control of the Postmating Behavioral Switch in Drosophila Females by Internal Sensory Neurons. Neuron 61, 519-526.

Yang, C.H., He, R., Stern, U., 2015b. Behavioral and circuit basis of sucrose rejection by Drosophila females in a simple decision-making task. J Neurosci 35, 1396-1410.

Yang, C.H., Rumpf, S., Xiang, Y., Gordon, M.D., Song, W., Jan, L.Y., Jan, Y.N., 2009b. Control of the postmating behavioral switch in Drosophila females by internal sensory neurons. Neuron 61, 519-526.

Yapici, N., Kim, Y.-J., Ribeiro, C., Dickson, B.J., 2008. A receptor that mediates the post-mating switch in Drosophila reproductive behaviour. Nature 451, 33-37. Yassin, A., Orgogozo, V., 2013. Coevolution between male and female genitalia in the Drosophila melanogaster species subgroup. PLoS One 8, e57158.

Zhang, G.-N., Hu, F., Dou, W., Wang, J.-J., 2012. Morphology and Distribution of Sensilla on Tarsi and Ovipositors of Six Fruit Flies (Diptera: Tephritidae). Annals of the Entomological Society of America 107, 319-327.

Zhu, Edward Y., Guntur, Ananya R., He, R., Stern, U., Yang, C.-H., 2014. Egg-Laying Demand Induces Aversion of UV Light in Drosophila Females. Current Biology 24, 2797-2804. 


\section{FIGURE LEGEND}

Figure 1. General layout of the information flow underlying egg-laying, and its evolution. (A) Schematic representation of the information flow governing insect oviposition. Mating triggers a change of internal state, sensed in part by peripheral sensory neurons. The information is relayed to higher brain centers, but also distributed to other organs and tissue involved in egg-laying. Together with other sensory information from the environment (substrate suitability, light), the mating state information is gated in the brain, resulting in the decision to lay an egg. Descending pathways, subjected to neuromodulation (e.g., as a result of photoperiod, or available options) activate motor circuits of the ventral nerve chord (VNC) controlling the oviposition machinery. These include central pattern generators (CPGs) that channel the egg down toward the ovipositor, coordinate the release of stored sperm to fertilize it, and control ovipositor movements necessary to deposit the egg into the substrate.

$(\mathbf{B}, \mathbf{C})$ Evolutionary changes in peripheral (B) and central (C) neuronal circuits likely to impinge on egg-laying behavior. 